\title{
Ongoing climate crises and obstacles to adaptation: Observations from the Ditsobotla Local Municipality, South Africa
}

\begin{tabular}{|c|c|}
\hline \multicolumn{2}{|c|}{$\begin{array}{l}\text { Authors: } \\
\text { Anica Pienaar }{ }^{1} \text { (] } \\
\text { Christo Coetzee }^{1} \text { (] } \\
\text { Livhuwani Nemakonde }^{1}\end{array}$} \\
\hline \multicolumn{2}{|c|}{$\begin{array}{l}\text { Affiliations: } \\
\text { }{ }^{1} \text { Department of Natural and } \\
\text { Agricultural Sciences, Faculty } \\
\text { of Environmental Science and } \\
\text { Management, North-West } \\
\text { University, Potchefstroom, } \\
\text { South Africa }\end{array}$} \\
\hline \multicolumn{2}{|c|}{$\begin{array}{l}\text { Corresponding author: } \\
\text { Anica Pienaar, } \\
\text { anipienaar@gmail.com }\end{array}$} \\
\hline \multicolumn{2}{|c|}{$\begin{array}{l}\text { Dates: } \\
\text { Received: } 26 \text { May } 2021 \\
\text { Accepted: } 21 \text { Sept. } 2021 \\
\text { Published: } 23 \text { Nov. } 2021\end{array}$} \\
\hline \multicolumn{2}{|c|}{$\begin{array}{l}\text { How to cite this article: } \\
\text { Pienaar A, Coetzee C, } \\
\text { Nemakonde L. Ongoing } \\
\text { climate crises and obstacles } \\
\text { to adaptation: Observations } \\
\text { from the Ditsobotla Local } \\
\text { Municipality, South Africa. } \\
\text { J transdiscipl res S Afr. } \\
\text { 2021;17(1), a1089. https:// } \\
\text { doi.org/10.4102/td. } \\
\text { v17i1.1089 }\end{array}$} \\
\hline \multicolumn{2}{|c|}{$\begin{array}{l}\text { Copyright: } \\
\text { ( 2021. The Authors. } \\
\text { Licensee: AOSIS. This wo } \\
\text { is licensed under the } \\
\text { Creative Commons } \\
\text { Attribution License. }\end{array}$} \\
\hline \multicolumn{2}{|l|}{ Read online: } \\
\hline 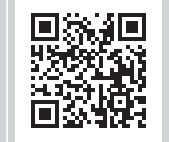 & $\begin{array}{l}\text { Scan this QR } \\
\text { code with your } \\
\text { smart phone or } \\
\text { mobile device } \\
\text { to read online. }\end{array}$ \\
\hline
\end{tabular}

Authors:

Anica Pienaar

Affiliations:

Aepartment of of Environmental Science and Management, North-West University, Potchefstroom

Corresponding author:

Anica Pienaar,

Dates:

Received: 26 May 2021 Accepted: 21 Sept. 2021

How to cite this article:

Pienaar A, Coetzee C,

Nemakonde L. Ongoing

from the Ditsobotla Local

.

2021;17(1), a1089. https://

doi.org/10.4102/td.

Licensee: AOSIS. This work

is licensed under the

Creative Commons

Attribution License.

mobile device

to read online.
Adaptation is a key component for fostering resilience amongst farmers as they are exposed to the challenges caused by climate change. However, the implementation of adaptation strategies is not equal or easy for most farming communities and are influenced by a diverse range of socio-economic constraints. In this context, the study intended to explore the factors constraining the implementation of climate change adaptation strategies amongst commercial and subsistence farmers of the Local Municipality in the North West province, South Africa. An exploratory sequential mixed method design was used, allowing the utilisation of both qualitative and quantitative methods in a single study. A total of 50 farmers (25 farmers from each group) were identified through purposive homogeneous sampling and were given a questionnaire consisting of semi-structured and structured questions. The study established that some of the most prominent factors constraining adaptation amongst farmers in the Local Municipality are related to their physical environment, lack of market access, financial constraints and limited access to established social networks (such as farmers associations). Identifying barriers to adaptation through area-specific research or studies, such as this particular study, is crucial for the development of holistic climate change adaptation strategies that will allow sustainability in diverse agricultural systems.

Keywords: agricultural adaptation strategies; climate change adaptation; coping capacity; disaster risk reduction; resilience; sustainable agriculture; vulnerability.

\section{Introduction}

The societies who build their livelihood around agriculture are becoming increasingly vulnerable during the 21st century as anthropogenic climate change is expected to have significant and pervasive effects because of deviating climatic conditions (e.g. drying) and the manifestation of extreme climatic events (e.g. drought). ${ }^{1,2,3}$ Many developing countries and their agricultural sectors are the most likely to be adversely affected by climate change as opposed to developed countries. ${ }^{4}$ The vulnerability of developing countries are often attributed to the centrality of agricultural activities in their economies and the lack of available and sufficient capital for implementing adaptation strategies. ${ }^{4,5}$ This also seems to be the case for South Africa and one of its provinces, the North West province (NWP). As stated by Elum et al., ${ }^{6}$ weather-related disasters, specifically droughts and floods, have had a long history in the NWP. This especially affects areas that are known to be highly dependent on agricultural activities for people's livelihoods, such as the local municipality. The vulnerability of South African farmers, and more specifically those located in the province, will increase in direct correlation with the occurrence of extreme weather events and unexpected variations in climate. $^{7}$

As such the aim of this article is to examine the factors that are restricting the commercial and subsistence farmers situated in the Ditsobotla Local Municipality from implementing climate change adaptation (CCA) strategies in their agricultural practices. Considering the challenges faced by both farming groups in a single study ultimately resulted in relevant recommendations for addressing the constraining factors that were identified in this study. In turn this could be used to facilitate the formulation of adaptation methods which are beneficial and applicable to both the commercial and subsistence farmers in the region. 


\section{Climate change and its predicted impact on South Africa's agriculture sector: A national and sub-national context}

South Africa has a dual agricultural economy consisting of a well-developed commercial sector, and a subsistence farming sector that makes significant contributions to rural livelihoods. ${ }^{8}$ As such agricultural land takes up roughly $80 \%$ or 100 million hectares of the total 121.9 million hectares of the country. ${ }^{9}$ It is estimated that more than half of the country's population depends on agriculture and agriculturalrelated industries for their livelihood, with almost 40000 commercial farmers and an estimated 2.8 million South African households involved in subsistence farming. ${ }^{8,9}$ Because of the presence of summer, winter and year-round rainfall areas, a wide variety of crop cultivation and livestock rearing activities are practised amongst both commercial and subsistence farmers. ${ }^{10}$

The vulnerability of South Africa's agricultural sector to the adverse effects of future climate change has been linked to the country's pre-existing classification as a semi-arid country, prevailing temperature and precipitation variations, increased farming activities on marginal lands, scarcity of water and frequent occurrences of droughts. ${ }^{9,1}$ As defined by the Intergovernmental Panel on Climate Change (IPCC) ${ }_{1}^{12}$ climate change refers to deviations in the state of the climate that can be observed through changes in the overall variability or the mean of its properties and is prevalent for an extended time, such as decades and longer. One of the major areas of concern relating to climate change is the impact thereof on existing water supplies. ${ }^{9,13}$ The availability of water is already one of the biggest constraints limiting the agricultural sector in South Africa with an estimated $60 \%$ of available water resources already being used for agricultural purposes and average annual precipitation of only $450 \mathrm{~mm}-500 \mathrm{~mm}$ per year, which is lower than the global precipitation average of $860 \mathrm{~mm} \cdot{ }^{6,8,14,15}$ In global terms, South Africa's water resources are referred to as being extremely limited and scarce, with projections suggesting that it would be one of the most water scarce countries in the world by $2025{ }^{6,7}$ Turpie and Visser ${ }^{10}$ paints an even more dire picture for the country indicating that the country's overall precipitation might decrease by as much as $6.3 \%$ by the year 2050 and $9.5 \%$ in 2080 because of the effects of climate change. Elum et al. ${ }^{6}$ states that South Africa is likely to be one of the countries that is most adversely affected by climate change on the African continent. Similar views are shared by Schlenker and Lobell ${ }^{16}$ who estimated an agricultural yield loss for South Africa of up to $30 \%$ by mid-century. Other studies suggest a decrease of $10 \%-20 \%$ in maize production over the next 50 years as a result of decreased precipitation brought on by climate change. ${ }^{17}$ The predicted impact of climate change on maize production is especially concerning as it constitutes the staple food for many communities in the country, whilst also accounting for $25 \%$ $33 \%$ of the total gross agricultural production in the whole country. ${ }^{18}$ Therefore, climate change could have food security, livelihood and economic implications for South Africa.
Research further indicates that some provinces and local municipalities in the country are likely to be more vulnerable and susceptible to variations in climate than others. ${ }^{8}$ Specifically, Turpie and Visser ${ }^{10}$ identified the North West, Free State and Limpopo provinces as the three provinces most likely to be adversely affected by climate change. All of these are arid areas that are especially vulnerable to future variations in climate. Additionally, the Department of Environmental Affairs ${ }^{7}$ proposes that the agricultural sector of the NWP is highly vulnerable to the impacts of climate change, accompanied by a concerning low adaptive capacity. Agriculture is a very important sector in the NWP having both large-scale commercial farmers and subsistence farmers. ${ }^{19,20}$ It is estimated that agricultural activities account for about $18 \%$ of the province's employment, making it the biggest source of employment in the NWP. ${ }^{19}$ One of the main attributes of this vulnerability is the dominating preference of maize production in the province. Maize and sunflower are extensively cultivated in the area, making the NWP one of the biggest maize producers in South Africa. ${ }^{7,18}$ However, this productive capacity greatly depends on the relationship between rainfall and crop production. Maize yield is known to be extremely sensitive to changes in precipitation patterns, which is predicted to become more erratic as the effects of climate change continues to manifest in the country. ${ }^{15,21}$ As such the potential implications of climate change could be devastating.

Studies indicate the NWP as one of the provinces experiencing drastic changes in rainfall patterns, which puts pressure on agricultural systems through reducing the areas suitable for agriculture, shortening growing periods and decreasing yield potential. ${ }^{4,22}$

The NWP is considered a dry region with the average annual rainfall ranging between $300 \mathrm{~mm}-600 \mathrm{~mm}$. Historically, droughts have always been a problem in the area with the district experiencing severe and persistent droughts in 1992, 2013 and 2015-2016. ${ }^{19}$ This existing proclivity for drought is only set to increase with the advent of climate change. ${ }^{18,23}$ Future projections of persistent droughts and variations of precipitation patterns show that there is a great threat for dryland and livestock agriculture in the province. ${ }^{6}$ Plausible future projections for the NWP during the latter part of the 21st century, in association with high mitigation efforts, include a temperature increase of $4^{\circ} \mathrm{C}$, with an increase in the occurrence of wet spells. ${ }^{15,24}$ Under low mitigation, circumstances include a drastic decrease in rainfall, accompanied by an increase in temperatures as large as $6^{\circ} \mathrm{C}$ in the far future..$^{25}$

Widely implemented dryland crops are generally more sensitive to variations in climate, whilst irrigated crops tend to be less vulnerable. ${ }^{5,9}$ However, because of the effect of climate change on rainfall patterns and water resources, the use of irrigation in the province will become increasingly limited. ${ }^{78}$ As the effects of climate change take hold in this region, maize harvests are expected to break even with production costs only every seven out of 10 years in the Ditsobotla Local Municipality area. ${ }^{7}$ This would mean that 
future maize production in the area will no longer be economically viable and should serve as a definite warning for the Province where maize is the most frequently cultivated crop. Both commercial and subsistence farmers in the region are likely to experience the detrimental effects of climate change, but there will be differences in how these two farming groups could be affected and the subsequent consequences.

Situated within the NWP, the Ditsobotla Local Municipality is considered to be one of the municipalities most vulnerable to variations in climate. ${ }^{10,26}$ Because of the local municipality's capacity for crop production, approximately $57 \%$ of the region is cultivated, with maize production constituting roughly $90 \%$ of all agricultural activity in the area. ${ }^{7,20}$

\section{Failure to adapt to a changing climate: Consequences for commercial and subsistence farmers}

Climate change has become an increasing challenge in the agricultural sector, and even more so for vulnerable farming communities in developing regions such as Africa. ${ }^{2,5}$ Climate change adaptation plays a crucial role in combating the potential effect of climate-induced disaster on agriculture. ${ }^{1,6}$ In the context of this study, CCA relates to adjustments to the established processes of farming systems to cope with current or foreseeable external climate stresses..$^{8,18,27}$

For commercial farmers, failure to adapt does not only entail extensive personal economic loss, but also affects their labour force (including their families), and the agricultural economy of that area. ${ }^{28}$ The demise of commercial farmers as a result of climate change could further aggravate food insecurity on a national level. Projections for the year 2050 estimates a net revenue loss of approximately $18 \%$ for South Africa's commercial agriculture, with a decline in maize production of between $12 \%$ and $40 \% .{ }^{10}$ Even more concerning is the fact that, by 2080 the net revenue loss is predicted to increase to $110 \%$, causing this sector to be completely unprofitable. ${ }^{10,28}$ Subsistence farmers, on the other hand, often lack the necessary resources to use anticipatory action against climate change compared to commercial farmers. ${ }^{13,29}$ Because of the nature of subsistence farming (i.e. producing for a households own subsistence), failure to adapt successfully could lead to various adverse consequences, including food insecurity, population dispersion, social disruption and instability and in extreme cases starvation. .,14,30 $^{4}$

Prominent differences currently exist between commercial and subsistence farmers' CCA rates and their ability to implement modern agriculture techniques and methods. ${ }^{8,11}$ Subsistence farmers constantly battle problems pertaining to the isolation of their agricultural businesses, that include almost no support structures, uncertain opportunities to participate in world markets and little to no access to technological advances. ${ }^{8}$ From the literature it is evident that whilst some studies suggest that subsistence farmers might be at higher risk to climate change owing to their limited ability to implement adaptation methods,, 931 others indicate commercial farmers to be the riskier sector because of higher investments in unstable and uncertain environmental and economic conditions. ${ }^{32}$ Regardless of which sector might be at higher risk, the ability of both to adapt to climate change is important for the survival and economic prosperity of vast populations. Understanding and considering the constraints to adaptation and their contributing factors when formulating adaptation strategies could facilitate improved integration of climate adaptation in their agricultural activities. ${ }^{32,33}$ This is further substantiated by Vincent, ${ }^{29}$ who argues that the identification of barriers to adaptation is crucial as it will only become harder to build sustainable adaptation methods, whilst the effect of climate change will continue to increase the vulnerability of developing countries such as South Africa. Some prominent barriers to climate adaptation by farming communities are unpacked in the following section.

\section{Common constraints to climate change adaptation within farming communities}

The implementation and planning of climate adaptation strategies are influenced by a diverse range of constraints in multiple contexts. ${ }^{6,34}$ Although literature tends to discuss each adaptation constraint individually, these factors rarely tend to act in isolation from each other. As a result, farmers are forced to navigate various interacting constraints to successfully reach a chosen adaptation objective. ${ }^{32,35}$ Roka $^{36}$ identifies three distinctive dimensions that may limit a farmer's decision to adapt, namely environmental/physical limits, which include access to natural resources; economic limits relating to financial capital, and lastly technological limits. Other prominent limitations include educational or experience related constraints, social and cultural constraints, and institutional constraints. ${ }^{25,29}$ The factors limiting farmers' use of appropriate adaptation strategies are discussed in the following section. These are general constraints that have emerged from literature; however it was important to highlight these constraints as some of them, if not all, might be applicable to the South African context.

\section{Environmental or physical limitations}

The environmental or physical transformations of an area because of climate change could affect a farmer's possibilities of adaptation. ${ }^{36,37}$ Climate attributes, namely precipitation and temperature, influence farmers' production and ultimately adaptation strategies, as they are forced to choose their livestock species and crop cultivars based on the climate of their surrounding environment. ${ }^{36,38}$

Lack of access to natural resources is another constraint that keeps farmers from adapting; for instance, the abundance or lack of water in an area highly susceptible to climate change could restrict the use of adaptation methods such as irrigation for farmers in the affected area. ${ }^{11,24,39}$ 


\section{Economic limitations}

Financial factors are also one of the main determinants of adaptation, with the most prominent constraints emerging from literature being a lack of credit, a limited financial capacity and the presence of poverty, especially amongst subsistence farming communities., ${ }^{31,32,39}$ Because of the adverse consequences of this barrier that limits a farmer's operations and adaptive capacity, financial limitations were also identified as a determining factor of vulnerability to climate change. ${ }^{40}$

\section{Access to technology and farm assets}

The use of technology often offers opportunities for adaptation. ${ }^{32}$ Key aspects that may promote or hinder the incorporation of technology in adaptation methods include its access, availability, and effectiveness for climate risk management purposes and the acceptance of technology by the users and relevant stakeholders. ${ }^{33,41}$

Farm assets such as heavy machinery facilitate the adoption of more advanced and effective adaptation methods. Literature shows a correlation between farm assets and the farmer's ability to adapt. ${ }^{42}$ Access to technology is one of the major points of differentiation between the adaptive capacity of subsistence and commercial farmers. Modern technologies are often more accessible to commercial farmers. ${ }^{8,29}$ However, in the absence of access to modern technologies, subsistence farmers often rely on innovative adaptation techniques based on traditional knowledge. ${ }^{43,44}$

\section{Education, awareness, perceptions and farming experience}

Education, farming experiences and perceptions are critical aspects that affect a farmers' decision to implement adaptation strategies. ${ }^{6,45,46}$ Knowledge and education on climate change, different agronomic practices and the potential benefits of adaptation enable farmers to respond to changes in climate more efficiently and to apply action specific measures. ${ }^{47}$ Awareness of climate change may urge farmers to use adaptation strategies in their agricultural activities if they know about the potential positive effect that adapting to climate change may have on their production. ${ }^{41,48}$ Of the previously mentioned adaptation barriers in this section, farming experience is thought to be the most influential factor prompting farmers to adapt. ${ }^{47,49}$ However, perceptions are formed based on climatic differentiations observed on a dayto-day and yearly basis. As a result, research indicates a greater relationship between a farmer's perceptions of climate change and short-term climatic events rather than long-term changes in climate. ${ }^{23,48}$ This causes significant challenges regarding the agricultural community's capacity to implement adaptation measures, as most CCA methods focus on the latter timeline of long-term changes in climate. ${ }^{27}$ Risk has an influence on what adaptation strategies a community might adopt or reject. A community's perception and knowledge of risk is consequently an important decision- making factor for the participants. ${ }^{50}$ This factor turns into a limitation if the individuals involved do not perceive long-term climate change risks as significant enough to warrant action.

\section{Social and cultural limitations}

Social and cultural barriers have been underestimated in past research. But in recent literature these factors have been emphasised as constraints of adaptation because of their influence on societal values, cultural norms and beliefs, and individuals' or communities' perception of risk. ${ }^{1,50,51}$ Various cultures and communities' approach and perceive predictions and knowledge of climate change differently. ${ }^{50,52}$ These variations in knowledge between communities testifies to the different values that persist and this could lead to adaptation constraints. ${ }^{52}$

Other social factors, for example social networks, can facilitate adaptation by spreading information about successful adaptation methods and climate change trends / predictions. $^{38} \mathrm{~A}$ different perspective that is not often mentioned as a limiting factor is the perceptions of farmers and the farming community of indigenous adaptation methods. An existing bias towards western information and the methods being more efficient have greatly undermined the mainstreaming of traditional adaptation methods. ${ }^{45,53}$ Consequently, the exclusion of indigenous adaptation methods could hinder the implementation of modern CCA methods by traditional farmers.

\section{Governance and institutional constraints}

According to Berman ${ }^{54}$ and the IPCC, ${ }^{33}$ public, municipal and private institutions all have an influence on local adaptation. These institutions are often interlinked and play a vital role in how local communities are affected by variations in climate and their ability to respond.

Biesbroek $^{34}$ proposes that governments are the primary actors in removing or creating factors hindering adaptation. Thus, governments could aid in the facilitation of adaptation and in comprehending the barriers that limits farmers' adaptive capacity. In other words, governments have the ability to constrain or enable adaptation at a national, regional or local level.

Before the results of the study are presented, a brief summary of the research design and methods applied will be outlined.

\section{Research methods and design}

The previous section briefly identified and discussed the existing literature pertaining to some of the major barriers to the adoption of climate adaptation measures in agricultural practices. This section gives an outline of the design and methodology applied to guide the study.

This study was conducted using an exploratory sequential approach. Specifically, the initial database of qualitative results and findings was used to guide the development of a second 
(quantitative) database. ${ }^{55}$ This design was best suited for the research as the initial qualitative inquiry allowed for the development and refinement of a quantitative instrument. ${ }^{56}$ The questionnaire was developed after the initial identification of prominent themes related to climate change and CCA from literature. From this literature review, a structured and semistructured questionnaire was formulated to collect qualitative and quantitative responses from participants. Purposive sampling was used to select the participant's representative of the commercial and subsistence farmers of the study region. ${ }^{57,58}$ Purposive homogeneous sampling was best suited for the selection of respondents as it permitted the researcher to gain sufficient information, whilst also representing the population as accurately as possible. Respondents for the sample size were selected based on whether they are commercial or subsistence farmers and the area in which they are situated within the Local Municipality. A total of 25 commercial and 25 subsistence farmers were selected, which allowed the researcher to collect information-rich data. As the farmers answered the questionnaire, a translator was present to translate phrases or questions if necessary.

To guide the data analysis for the study a thematic analysis approach was chosen for the first phase, in order to identify patterns in the information or data collected. ${ }^{59,60}$ The data collected from the questionnaires was then analysed by means of a deductive content analysis approach. Content analysis is a systematic analysis that involves the classification of text by means of a systematic coding scheme to ultimately form knowledgeable conclusions of the information. The approach was suitable for this particular data set because of its flexibility, permitting the researcher to evaluate and interpret the data gathered by means of both the semi-structured and structured questions. ${ }^{61}$

\section{Ethical considerations}

This study was conducted with the approval of NWU's Natural and Agricultural Sciences ethics committee and adhered to all the conditions and guidelines set out by the committee (reference number: NWU-01291-20-A9). The participants were informed of the purpose of the research, their anonymity and that their participation was strictly voluntary.

\section{Results}

\section{Impact of climatic changes on Ditsobotla Local Municipality}

The majority (76\%) of farmers (38 of 50 participants as illustrated in Figure 1) observed changes or variations in temperatures and increased variations or changes in rainfall patterns in their farming practices and immediate environment. One of the commercial participants observed 'unpredictable rainfall seasons' along with a subsistence farmer claiming that 'rainfall patterns have changed, and droughts are more frequent'. When disaggregating the data per farming group, a significant overlap, as is evident from Figure 1, emerged in the environmental changes observed by the subsistence and commercial farmers in their surrounding areas. Changes and variations in temperature was the most observed by $80 \%(N=20)$ commercial farmers and $44 \%(N=11)$ subsistence farmers. Variations and changes in rainfall (i.e. irregular and sporadic rainfall patterns) followed with $36 \%(N=9)$ for commercial respondents and $36 \%(N=9)$ for subsistence respondents, and lastly higher frequencies and more intense droughts were mentioned by $20 \%(N=5)$ of the commercial farmers and $28 \%(N=7)$ of the subsistence farmers.

The environmental changes observed by the respondents (Figure 1) correlate with the proposed effects climate change could have on the region according to literature discussed under the section titled 'Climate change and its predicted impact on South Africa's agriculture sector: A national and sub-national context'. In addition to the common observations mentioned, a unique observation was made by a commercial farmer who said, 'plants with a higher woody content and of lower nutritional value are replacing the grass and plants with a higher nutritional value in the field'. This could suggest an overall decline in the levels of agricultural fertility in the area.

Both farming groups were also asked to what extent they believe climate change already has or might have an impact on their agricultural activities. With regard to the impacts of climate change on their agricultural activities, most commercial farmers indicated that climate change has / might have a severe impact on their agricultural activities $(88 \%$ [ $N=22])$, with only $12 \%(N=3)$ believing it to have a moderate impact. To the same inquiry subsistence farmers gave varying answers with the primary being that climate change has a severe impact on their agricultural practices $(40 \%[N=10])$. Of the other subsistence farmers, about $24 \%$ $(N=6)$ believed it to have a moderate effect and $16 \%(N=4)$ believed that it has little impact. Therefore, there seems to be some difference between the groups relating to their perceived impact of climate change, with commercial farmers experiencing the impact of climate change to a greater extent

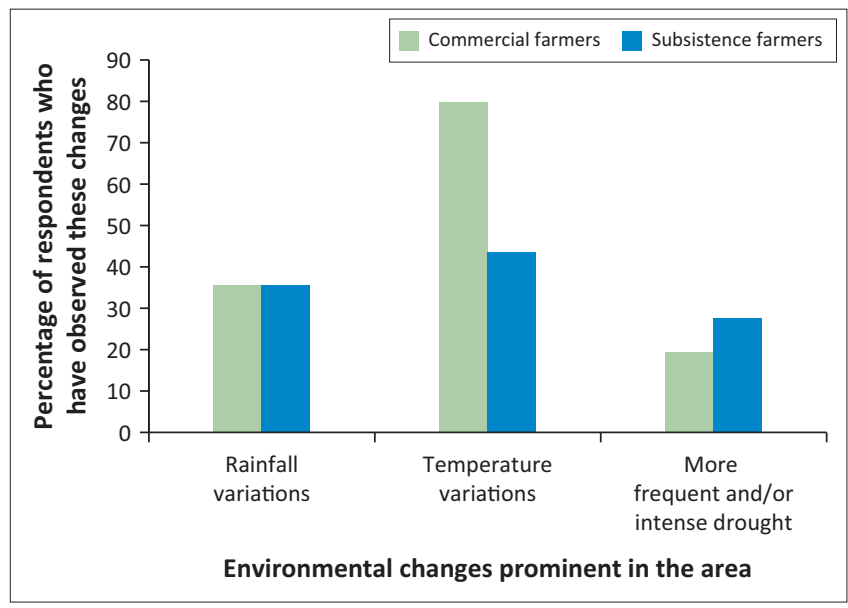

FIGURE 1: Environmental changes observed by respondents. 
than their subsistence counterparts. In this regard, a commercial farmer acknowledged:

'There are huge risks connected to climate change. Only one unfavourable harvesting year could cause my downfall due to all the financial constraints.' (Commercial Farmer, Participant 9, Male, Age Group 41-50 years)

\section{Factors constraining subsistence farmer respondents}

The farmers participating in the study were able to identify the factors (presented in Figure 2) that hinder CCA in their area. Structured questions were asked in Likert-scale form (on a scale of never, rarely, regularly, almost always and always) to establish relevance and not simply the applicability of the questions. The Likert-scale data were processed for the formulation of charts through assigning value to each rating on the Likert-scale, calculating the mean scores of each variable and creating charts based on the results. According to the scores listed in Table 1, the biggest issue for subsistence farmers was a lack of access to machinery (extremely high number of $99.2 \%$ ), which also corresponds to the literature presented under section Access to technology and farm assets. Whilst the main driver for commercial farmers to operate within a highly mechanised environment is to increase their yields, their access to machinery also increases their resilience to climate change through minimising their dependence and use of only natural resources. A lack of access to chemicals was

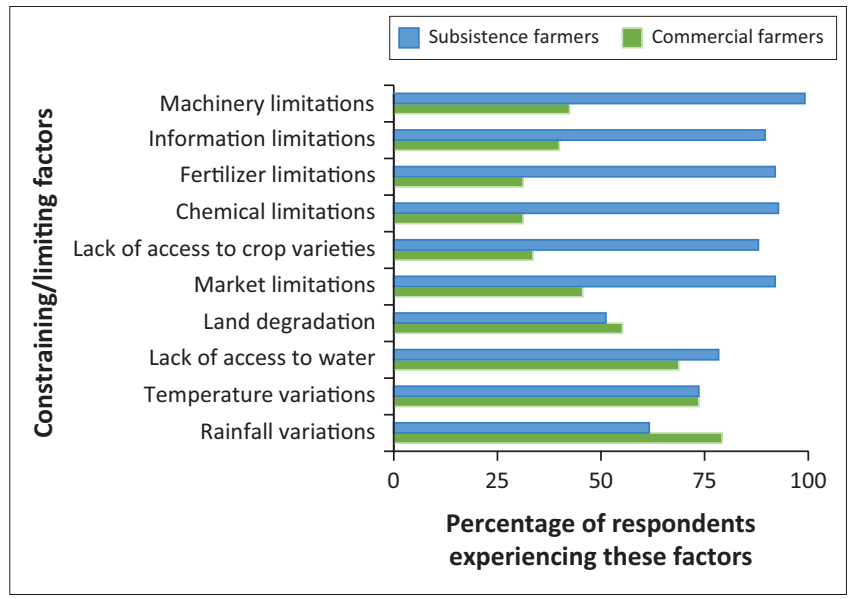

FIGURE 2: Factors constraining the adaptation of respondents.

TABLE 1: Scores of the factors constraining respondents from adapting to climate change.

\begin{tabular}{llcc}
\hline & Factors limiting CCA & CF Score & SF Score \\
\hline 1 & Variations in rainfall & 3.960 & 3.080 \\
2 & Variations in temperature & 3.680 & 3.680 \\
3 & Lack of access to water & 3.440 & 3.920 \\
4 & Land degradation & 2.760 & 2.560 \\
5 & Lack of access to markets & 2.280 & 4.600 \\
6 & Lack of access to crop varieties & 1.680 & 4.400 \\
7 & Lack of access to chemicals & 1.560 & 4.640 \\
8 & Lack of access to fertilisers & 1.560 & 4.600 \\
9 & Lack of access to information & 2.000 & 4.680 \\
10 & Lack of access to machinery & 2.120 & 4.960 \\
& Average & $\mathbf{2 . 5 0 4}$ & $\mathbf{4 . 0 9 2}$ \\
\hline
\end{tabular}

CCA, climate change adaptation; CF, commercial farmers; SF, subsistence farmers. identified as the second biggest limiting factor (an estimated 93\%).This factor is associated with economic limitations, a category that was emphasised throughout literature because of subsistence farmers' predominantly restricted access to financial resources. Lack of access to markets $(92 \%)$ and lack of access to fertilisers (92\%) followed closely. The farmers were also given a chance to elaborate on any additional limitations they might experience that have not been included in the questionnaire. A few of the responses identified a lack of access to land, more specifically as one farmer stated, 'access to healthy land', pertaining to the issue of land degradation, or 'access to larger areas of land' as indicated by another. To increase the implementation rates of adaptation strategies, it is therefore important to acknowledge that the greatest challenges subsistence farmers in the area need to overcome often relates to economic and productive factors.

\section{Factors constraining commercial farmer respondents}

With reference to Figure 2, deriving from the scores of Table 1, the greatest limiting factor for the commercial farmers was variations and/or changes in rainfall (almost $80 \%$ ), which has an overall rating of 'almost always'. Variations and/or changes in temperature was the second greatest factor limiting adaptation for them (about 74\%), followed closely by a lack of access to water (69\%).

\section{Discussion}

The inquiry into the influence of climate change on the agricultural sector of the NWP and the local municipality revealed the high vulnerability of the farmers in the locale accompanied by increasingly challenging environmental issues in the near future. The heightened awareness of climate change impacts amongst commercial farmers might be linked to the scale of their investments in operations, production assets and livelihood, both presently and because of probable future circumstances. On the contrary, the varying answers given by the subsistence respondents could reflect their risks associated with climate change owing to their relatively smallscale operations and different livelihood sources, which could help offset the extent to which climate change could have an impact on their agricultural operations. ${ }^{32}$

What was clear from both these lines of questioning was that farmers were generally well aware of the impact of anthropogenic climate change as they could observe significant climatic changes in the environment. Furthermore, the shift in the climate could already be felt in their agricultural production and economic outputs. However, in spite of these clear observations the reality exists that different farming groups, that is, commercial and subsistence farmers, might have disparate abilities in being able to adapt to future climate change. These differences are important to identify if governments are to develop holistic and context-specific adaptation strategies.

The information obtained from the farmers who participated in the study also substantiates the claims of climate change 
manifesting as changes and/or variations in temperatures and increased changes and/or variations in rainfall patterns. These were also found to be the greatest limiting factors amongst commercial respondents as variations and/or changes in rainfall patterns were identified by about $79 \%$ of the respondents and variations and/or changes in temperature by about $74 \%$. For them, the biggest limiting factors were based on the difficult environmental challenges and the pace at which these changes are happening, so much so that they cannot adapt to the changing climate quickly enough. As the qualitative investigation of this study suggests, these challenges are likely to intensify as climate change continues to manifest during this century. Enabling these farmers to adapt efficiently to the adverse effects of climate change is imperative so that they, along with the families dependent on commercial farming for their livelihood, can continue to contribute to South Africa's agricultural sector and economy. As presented in Figure 2 and Table 1, the factors hindering the subsistence farmers from adapting were mostly related to their limited access to agricultural machinery (99.20\%) and chemicals (92.80\%). Unfortunately, limitations are rarely mutually exclusive, in the case of the subsistence farmers their lack of access to basic agricultural products are the result of a combination of economic and productive limitations. Without access to basic agricultural products such as chemicals or fertilisers, their crops will likely be less resilient to the impacts of climate change such as increased temperatures or crop diseases. In turn this could have a detrimental effect on the food security and health of subsistence households as they are directly dependent on their crops to meet their food consumption needs. ${ }^{4,32}$

A crucial challenge that limits the adaptation to climate change identified by both the groups of farmers is the lack of financial support by the government. Considering that both groups of farmers agree on financial limitation as a key constraint to climate adaptation, the government should ensure that any future CCA strategy should incorporate financial tools, mechanisms and strategies that support adaptation efforts by all farming groups. These farmers constantly battle unstable environmental, economic and political conditions. Those who have access to markets are often met with very low prices for their products, often causing their agricultural yield to be unprofitable, whilst those who do not have access to markets are also left with immense challenges when attempting to meet their basic food needs. Arguably, these could also reduce the adaptive ability and the overall levels of resilience. To help farmers navigate the detrimental effects of climate change within their environment, it is important to facilitate the creation of location-specific adaptation strategies. Asking the individuals most affected by the detrimental impacts of climate change about what they believe could eliminate the factors that prevent them from adapting is a great starting point for location-specific adaptation initiatives.

From the subsistence respondents' perspective, the adaptive capacity of farming communities could be improved significantly by financial aid and with increased access to resources such as materials for shelters, information resources and access to water resources. Some respondents also mentioned access to land as another method of improving the adaptive capacity of these communities. One subsistence farmer alluded to the problems that farmers face with regard to livestock theft as he told that his 'chickens are being stolen by individuals living in the neighbouring communities'. This indicates that increased security and stricter laws could improve the coping capacity of livestock farmers.

Most of the commercial farmers believed that the dissemination of climate change related information and the sharing of knowledge between farmers could improve the adaptive capacity of rural communities. They also highlighted government aid and financial relief as ways to build the resilience of their communities. One commercial respondent in particular mentioned 'agricultural extension officers should be more accessible' and that 'mentorship should be encouraged'. A noteworthy recommendation mentioned by another commercial farmer was that 'the government should promote cohesion between all farming groups', which in turn could also increase the adaptive capacity of farming communities.

Consideration of the specific environmental characteristics of the areas these farmers farm in could result in more effective adaptation strategies with a higher implementation rate. However, this is not the only threat to agricultural systems in the area. Increasingly challenging circumstances surrounding the local municipality's natural environment are often accompanied by discouraging political influences. The sentiment that the financial input required for successful agricultural production is no longer justifying the economic outcomes was emphasised throughout the study, especially by commercial farmers. To alleviate the limitations pertaining to financial factors, increased government aid is needed, especially for the commercial and subsistence farmers that are already established within their communities.

Finally, the value of the indigenous knowledge of these established farming communities should not be overlooked in the formulation of modern adaptation strategies. Taking into account the potential benefits of using indigenous knowledge in CCA strategies, such as increased adoption rates and creative cost-effective solutions, an all-inclusive approach should be mainstreamed globally with more adaptation options specifically suited to the communities and their locations.

\section{Strengths and limitations}

The research aimed to provide a significant contribution to knowledge, in both theory and practice, about the factors impeding the implementation of CCA methods by the commercial and subsistence farmers of a local municipality in the NWP. The information collected could serve as a comparative reference point for facilitating the improved adaptive capacity of agricultural communities. However, the 
study has potential limitations. The research is mainly confined to the Ditsobotla Local Municipality context. Therefore, it is not assumed that all findings, including the CCA methods implemented by these farmers and the challenges they face, could be generalised to other regions and farming groups within the country or to other countries. However, the study might provide insights into the factors leading to difference in CCA methods chosen by commercial and subsistence farmers, as well as the importance of improving agricultural communities' ability to respond effectively to climate change. Lack of access to a list of the population being studied, in this case subsistence farmers, eliminated the application of probability sampling. In turn the application of a non-probability sampling method restricted the generalisability of the findings. Nevertheless, non-probability sampling methods are useful in exploratory mixed methods research, especially for developing a complete understanding of the complex issues relating to human behaviour such as adaptation to climate change.

\section{Implications or recommendations}

The findings from this study emphasises the need for further research on relevant topics. Opportunities for future research include the following:

1. Further research is needed to better facilitate the integration of CCA strategies within the agricultural communities of developing countries, as the theoretical investigation suggested that these countries will be the most affected by climate change. Strategies should specifically be designed for and be applicable to the locations and circumstances of the target communities.

2. The study identified the various aspects that keep farmers from adopting some strategies that could enhance their resilience to the impact of climate change. However, an investigation of a greater scope of the barriers to adaptation could aid in promoting more focused action towards addressing these issues.

3. In the Ditsobotla Local Municipality, there is a need to improve communication between the government and farming communities, especially in the case of subsistence farmers. A lack of information was found to be a primary constraint of CCA for them.

4. This study highlighted the need for enhancing the adaptive capacity of vulnerable farming communities, such as those situated in the study area. There is scope for further inquiry into effective approaches for strengthening their capacity to adapt.

5. The emotion and passion evident in the respondents' answers were a true testament of the hardships and difficult circumstances surrounding agriculture in South Africa. Most CCA literature gives detailed descriptions of the possible limitations that commercial and subsistence farmers might face, but very few address the issue of their emotional well-being in the face of challenging circumstances and climate change. Further research on this topic could help emphasise the importance of adaptation facilitation by governmental structures.

\section{Conclusion}

The impending effects of climate change on the natural resources of developing countries make those dependent on agriculture vulnerable to variations in climate and occurrences of extreme weather events. The steadily declining state of agriculture owing to climate change manifesting in the form of increased temperatures, longer periods of drought and irregular rainfall patterns in the Ditsobotla Local Municipality and regions alike, greatly threatens the sustainability of their commercial and subsistence farming communities.

The inquiry into existing literature revealed three distinctive dimensions that may limit a farmer's ability to adapt. These were environmental and/or physical limits, which includes access to natural resources and recurrent droughts; economic limits relating to financial capital; and lastly technological limits, which relates to a farmer's accessibility to modern farming equipment and heavy machinery. During the study, different factors were found to have the potential of improving or constraining the adaptive capacity of the respective farming groups. The common limitations hindering both the farming groups from adopting other strategies were variations in temperatures, financial factors and a lack of governmental support. Additionally, there was also a difference in some of the limitations these farmers face. The results of the structured questions revealed that commercial farmers were primarily hindered by adverse and uncertain environmental circumstances, whilst subsistence farmers face a diverse array of limitations, including environmental, technological, and market-related aspects. However, these factors should not be identified as a means of deciding which farming system should receive priority for support. This study has emphasised the importance of increasing the adaptive capacity of all farmers. The differentiating factors should rather be used to formulate appropriate responses to ensure the sustainability of all agricultural systems. If governing bodies seize the opportunity to enhance the adaptive capacity of local farming communities, they are sure to find resilient and determined farmers with a willingness to participate in adaptation processes.

\section{Acknowledgements Competing interests}

The authors declare that they have no financial or personal relationships that may have inappropriately influenced them in writing this article.

\section{Authors' contributions}

A.P. contributed to the conceptualisation, design and implementation of the research, to the analysis and curation of the results, and to the writing of the manuscript. C.C. supervised the research, contributed to the conceptualisation of the work and writing of the manuscript, to the critical revision of the manuscript, and to the approval of the version to be published. L.N. supervised the work, contributed to the critical revision of the manuscript, and to the approval of the version to be published. 


\section{Funding information}

The authors declare that they have no financial or personal relationships that may have inappropriately influenced them in writing this article.

\section{Data availability}

The data that support the findings of this study are not publicly available because of privacy restrictions. Data are available from the corresponding author, A.P, upon reasonable request.

\section{Disclaimer}

The views and opinions expressed in this article are those of the authors and do not necessarily reflect the official policy or position of any affiliated agency of the authors.

\section{References}

1. Joshi NP, Maharjan KL. Climate change, agriculture and rural livelihoods in developing countries. Tokyo: Springer; 2013

2. Awojobi ON, Tetteh J. The impacts of climate change in Africa: A review of the scientific literature. JIARM. 2017;5(11):39-52.

3. Thakur SB, Bajagain A. Impacts of climate change on livelihood and its adaptation needs. JAE. 2019;20(2019):173-185. https://doi.org/10.3126/aej.v20i0.25067

4. Altieri $\mathrm{MA}$,Nicholls $\mathrm{Cl}$. The adaptation and mitigation potential of traditional agriculture in a changing climate. Clim Change. 2017;140:33-45. https://doi. org/10.1007/s10584-013-0909-y

5. Lalego B, Ayalew T, Kaske D. Impact of climate variability and change on crop production and farmers' adaptation strategies in Lokka Abaya district, Southern Ethiopia. Afr J Environ Sci Technol. 2019;13(3):1-11.

6. Elum ZA, Modise D, Marr A. Farmer's perception of climate change and responsive strategies in three selected provinces of South-Africa. Clim Risk Manag. 2017;16:246-257. https://doi.org/10.1016/j.crm.2016.11.001

7. South Africa. Department of Environmental Affairs. Climate support program: Vulnerability assessment. Report for North West province. Pretoria: Department of Environmental Affairs, 2015.

8. Schulze RE. Agriculture and climate change in South Africa: On vulnerability, adaptation and climate smart agriculture. In: Schulze RE, editors. Handbook on adaptation to climate change for farmers, officials and others in the agricultural sector of South Africa. Pretoria: DAFF: Thematic Booklet 1, 2016; p.1-103.

9. Lotter. Risk and vulnerability in the South African farming sector: Implications for sustainable agriculture and food security. In: Mambo J, Faccer K, editors. Understanding the social \& environmental implications of global change. Stellenbosch: African Sun Media, 2017; p. 67-75.

10. Turpie J, Visser M. The impact of climate change on South Africa's rural areas. Financ Fiscal Comm. 2014;14:100-160.

11. Quinn CH, Ziervogel G, Taylor A, Takama T, Thomalla F. Coping with multiple stresses in rural South Africa. Ecol Soc. 2011;16(3):1-10.https://doi.org/10.5751/ ES-04216-160302

12. IPCC (Intergovernmental Panel on Climate Change). Managing the risks of extreme events and disasters to advance climate change adaptation. A special report of working groups I and II of the IPCC. Cambridge: Cambridge University Press; 2012.

13. Pereira L. Climate change impacts on agriculture across Africa. In: Oxford research encyclopedia of environmental science. Oxford: Oxford University Press; 2017.

14. Zwane EM. Impact of climate change on primary agriculture, water sources and food security in Western Cape, South Africa. JAMBA. 2019;11(1):1-7. https://doi. org/10.4102/jamba.v11i1.562

15. Welborn L. Africa and climate change: Projecting vulnerability and adaptive capacity. Institute for Security Studies Africa Report. 2018;14:1-24.

16. Schlenker W, Lobell DB. Robust negative impacts of climate change on African agriculture. Environ. 2010;5(1):014010. https://doi.org/10.1088/17489326/5/1/014010

17. Oduniyi OS, Antwi MA, Tekana SS. Prioritization on cultivation and climate change adaptation techniques: A potential option in strengthening climate resilience in South Africa. Agron Colomb. 2019;37(1):62-72. https://doi.org/10.15446/agron. colomb.v37n1.77545

18. Oduniyi OS. Implication of climate change on livelihood and adaptation of small and emerging maize farmers in the North West province of South Africa [unpublished thesis]. Pretoria: University of South Africa; 2018.

19. South Africa. Department of Rural Development and Land Reform. District rural development plan: Ngaka Modiri Molema District Municipality. North West province. Pretoria: Department of Rural Development and Land Reform, 2016.
20. Savannah Environmental. Social impact assessment scoping report for the Lichtenburg 2 PV facility near Lichtenburg in the North West province [homepage on the Internet]. 2018 [2019 Jan 3]. Available from: sahris.sahra.org.za ) files , on the Internet]. 2018 [2019 Jan 3]. Available
additionaldocs > 0.LichtenburgPV2 - FEIA.pdf

21. Blignaut J, Ueckermann L, Aronson J. Agriculture production's sensitivity to changes in climate in South Africa. S Afr J Sci. 2009;105(1):61-68. https://doi. org/10.4102/sajs.v105i1/2.4

22. Mambo J, Murambadoro M. Municipal vulnerability to climate change. In: Mambo J, Faccer $K$, editors. Understanding the social \& environmental implications of global change. Stellenbosch: African Sun Media, 2017; p. 113-120.

23. Wiid N, Ziervogel G. Adapting to climate change in South Africa: Commercial farmers' perception of and response to changing climate. S Afr Geogr J. 2012;94(2):152-173. https://doi.org/10.1080/03736245.2012.742783

24. Ziervogel G, New M, Archer van Garderen E, et al. Climate change impacts and adaptation in South Africa. Wiley Interdiscip Rev Clim Change. 2014;5(5):605-620. https://doi.org/10.1002/wcc.295

25. South Africa. Department of Environmental Affairs. South Africa's third national communication: Under the United Nations Framework Convention on climate change. Pretoria: Department of Environmental Affairs; 2018.

26. Le Roux A, Mans G, Van Huyssteen E, Van Niekerk W. Profiling the vulnerabilities and risks of South African settlements. In: Mambo J, Faccer K, editors. Understanding the social \& environmental implications of global change. Stellenbosch: African Sun Media, 2017; p. 26-35.

27. Bryan E, Ringler C, Okoba B, Roncoli C, Silvestri S, Herrero M. Adapting agriculture to climate change in Kenya: Household strategies and determinants. Environ Manage. 2013;114:26-35. https://doi.org/10.1016/j.jenvman.2012.10.036

28. Nhamo L, Matchaya G, Mabhaudhi T, Nhlengethwa S, Nhemachena C, Mpandeli S. Cereal production trends under climate change: Impacts and adaptation strategies in Southern Africa. Agriculture. 2019;9(30):1-16. https://doi.org/10.3390/ agriculture9020030

29. Vincent K, Joubert A, Cull T, Magrath J, Johnston P. Overcoming the barriers: How to ensure future food production under climate change in Southern Africa. to ensure future food production under
Oxford: Oxfam Research Report, 2011; p.59.

30. Tibesigwa B, Visser M. Small-scale subsistence farming, food security, climate change and adaptation in South Africa: Male-female headed households and urban-rural nexus. Economic Research Southern Africa, Working Paper 527; 2015.

31. Cohn AS, Newton P, Gil JDB, et al. Smallholder agriculture and climate change. Ann Rev Environ Res. 2017;42(1):347-375. https://doi.org/10.1146/annurevenviron-102016-060946

32. Yaro JA. The perception of and adaptation to climate variability/change in Ghana by small-scale and commercial farmers. Reg Environ Change. 2013 13(6):1259-1272. https://doi.org/10.1007/s10113-013-0443-5

33. IPCC (Intergovernmental Panel on Climate Change). Adaptation opportunities, constraints, and limits. Contribution of working group ii to the fifth assessment report of the Intergovernmental Panel on Climate Change. Cambridge: Cambridge University Press; 2014.

34. Biesbroek GR, Klostermann JEM, Termeer CJAM, Kabat P. On the nature of barriers to climate change adaptation. Reg Environ Change. 2013;13:1119-1129. https:// to climate change adaptation. Reg Envir
doi.org/10.1007/s10113-013-0421-y

35. Shen $L Y$, Ochoa JJ, Shah MN, Zhang X. The application of urban sustainability indicators: A comparison between various practices. Habitat Int. 2011;35:17-29. https://doi.org/10.1016/j.habitatint.2010.03.006

36. Roka K. Climate change adaptation. In: Filho WL, Azul AM, Brandli L, Ozuyar PG, Wall T, editors. Climate action. Cham: Springer Nature, 2020; p. 97-108.

37. Adger WN, Dessai $S$, Goulden $M$, et al. Are there social limits to adaptation to climate change? Clim Change. 2009;93(3):335-354. https://doi.org/10.1007/ s10584-008-9520-z

38. Gbetibouo GA, Ringler C, Hassan R. Vulnerability of the South African farming sector to climate change and variability: An indicator approach. Nat Res Forum. sector to climate change and variability: An indicator approach. Nat Res
2010;34(3):175-187. https://doi.org/10.1111/j.1477-8947.2010.01302.x

39. IPCC (Intergovernmental Panel on Climate Change). Africa. Contribution of Working Group II to the Fifth Assessment Report of the Intergovernmental Panel on Climate Change. Cambridge: Cambridge University Press; 2014.

40. Padgham J. Agricultural development under a changing climate: Opportunities and challenges for adaptation. Washington, DC: The World Bank Environment Department; 2009.

41. Nhemachena C, Hassan R, Chakwizira J. Analysis of determinants of farm-level adaptation measures to climate change in Southern Africa. J Dev Agric Econ. 2014;6(5):232-241.

42. Hassan R, Nhemachena C. Determinants of African farmers' strategies for adapting to climate change: Multinomial choice analysis. Afr J Agr Res Econ 2008;2(1):83-104

43. Nyong $A$, Adesina $F$, Elasha $O B$. The value of indigenous knowledge in climate change mitigation and adaptation strategies in the African Sahel. Mitig Adapt Strateg Glob Chang. 2007;12(5):787-797. https://doi.org/10.1007/s11027-007-9099-0

44. Ajani EN, Mgbenka RN, Okeke MN. Use of indigenous knowledge as a strategy for climate change adaptation amongst farmers in sub-saharan Africa: Implications for policy. AJAEES. 2013;2(1):23-40. https://doi.org/10.9734/AJAEES/2013/1856

45. Buchmann C, Darnhofer I, Grotzer M. Farming systems dynamics: The quest for a methodology to measure social-ecological resilience in subsistence agriculture. In: Proceedings of the 9th European IFSA symposium, 'Building sustainable rural futures: The added values of systems approaches in times of change and uncertainty'. Wien, 2010; p. 4-7.

46. Milfont TL. The interplay between knowledge, perceived efficacy, and concern about global warming and climate change: A one-ear longitudinal stuc Anal. 2012;32(6):1003-1020. https://doi.org/10.1111/j.1539-6924.2012.01800.x 
47. Wolf J, Moser SC. Individual understandings, perceptions, and engagement with climate change: Insights from in-depth studies across the world. Wiley Interdiscip Rev Clim Change. 2011;2(4):547-569. https://doi.org/10.1002/wcc.120

48. Marshall NA, Park S, Howden SM, Dowd AB, Jakku ES. Climate change awareness is associated with enhanced adaptive capacity. Agric Syst. 2013:117:30-34. https://doi.org/10.1016/j.agsy.2013.01.003

49. Niles MT, Lubell M, Brown M. How limiting factors drive agricultural adaptation to climate change. Agric Ecosyst Environ. 2015;200:178-185. https://doi. org/10.1016/j.agee.2014.11.010

50. Wolf J, Allice I, Bell T. Values, climate change, and implications for adaptation: Evidence from two communities in Labrador, Canada. Glob Environ Change. 2013;23(4):548-562. https://doi.org/10.1016/j.gloenvcha.2012.11.007

51. O'Brien KL, Wolf J. A values-based approach to vulnerability and adaptation to climate change. Wiley Interdiscip Rev Clim Change. 2010;1(2):232-242. https:// doi.org $/ 10.1002 /$ wcc.30

52. Adger WN, Barnett J, Brown K, Marshall N, O'Brien KL. Cultural dimensions of climate change impacts and adaptation. Nat Clim Change. 2013;3:112-117. https://doi.org/10.1038/nclimate1666

53. Green D, Raygorodetsky G. Indigenous knowledge of a changing climate. Clim Change. 2010;100:239-242. https://doi.org/10.1007/s10584-010-9804-y
54. Berman R, Quinn C, Paavola J. The role of institutions in the transformation of coping capacity to sustainable adaptive capacity. Environ Manage. 2012:2:86-100. https://doi.org/10.1016/j.envdev.2012.03.017

55. Creswell JW. Research design: Qualitative, quantitative and mixed methods approaches. 4th ed. Thousand Oaks, CA: Sage; 2014.

56. Fetters MD, Curry LA, Creswell JW. Achieving integration in mixed methods designs- principles and practices. Health Serv Res. 2013;48(6):2134-2156. https:// doi.org/10.1111/1475-6773.12117

57. Teddlie C, Yu F. Mixed methods sampling: A typology with examples. J Mix Meth Res. 2007;1(1):77-100. https://doi.org/10.1177/1558689806292430

58. Etikan I, Musa SA, Alkassim RS. Comparison of convenience sampling and purposive sampling. ATJAS. 2016;5(1):1-4. https://doi.org/10.11648/j.ajtas.20160501.11

59. Vaismoradi $\mathrm{M}$, Turunen $\mathrm{H}$, Bondas $\mathrm{T}$. Content analysis and thematic analysis: Implications for conducting a qualitative descriptive study. Nurs Health Sci. 2013;15(3):398-405. https://doi.org/10.1111/nhs.12048

60. Nowell L, Norris J, White D, Moules N. Thematic analysis: Striving to meet the trustworthiness criteria. Int J Qual Methods. 2017;16(1):1-13. https://doi. org/10.1177/1609406917733847

61. Bengtsson M. How to plan and perform a qualitative study using content analysis. Nursing Plus Open. 2016;2:8-14. https://doi.org/10.1016/j.npls.2016.01.001 